\title{
Proteomic Changes in the Sound Vibration-Treated Arabidopsis thaliana Facilitates Defense Response during Botrytis cinerea Infection
}

\author{
Ritesh Ghosh $\mathbb{B D}^{1 \dagger}$, Bosung Choi ${ }^{1 \dagger}$, Young Sang Kwon ${ }^{2}$, Tufail Bashir ${ }^{1}$, Dong-Won Bae ${ }^{3 *}$, and Hanhong Bae ${ }^{1 *}$ \\ ${ }^{1}$ Department of Biotechnology, Yeungnam University, Gyeongsan 38541, Korea \\ ${ }^{2}$ Environmental Toxicology Research Center, Korea Institute of Toxicology, Jinju 52834, Korea \\ ${ }^{3}$ Central Instrument Facility, Gyeongsang National University, Jinju 52828, Korea
}

(Received on November 7, 2018; Revised on January 2, 2019; Accepted on October 7, 2019)

Sound vibration (SV) treatment can trigger various molecular and physiological changes in plants. Previously, we showed that pre-exposure of Arabidopsis plants to SV boosts its defense response against Botrytis cinerea fungus. The present study was aimed to investigate the changes in the proteome states in the SV-treated Arabidopsis during disease progression. Proteomics analysis identified several upregulated proteins in the SVinfected plants (i.e., SV-treated plants carrying Botrytis infection). These upregulated proteins are involved in a plethora of biological functions, e.g., primary metabolism (i.e., glycolysis, tricarboxylic acid cycle, ATP synthesis, cysteine metabolism, and photosynthesis), redox homeostasis, and defense response. Additionally, our enzyme assays confirmed the enhanced activity of antioxidant enzymes in the $\mathrm{SV}$-infected plants compared to control plants. Broadly, our results suggest that $\mathrm{SV}$ pre-treatment evokes a more efficient defense response in the $\mathrm{SV}$-infected plants by modulating the primary

\footnotetext{
${ }^{\dagger}$ These authors contributed equally to this work.

*Co-corresponding authors.

Hanhong Bae

Phone) +82-53-810-3031, FAX) +82-53-810-4769

E-mail) hanhongbae@ynu.ac.kr

Dong-Won Bae

Phone)+82-55-772-0672, FAX) +82-55-772-0669

E-mail)bdwon@gnu.ac.kr

ORCID

Ritesh Ghosh

https://orcid.org/0000-0002-2528-7277

(c) This is an Open Access article distributed under the terms of the Creative Commons Attribution Non-Commercial License (http:// creativecommons.org/licenses/by-nc/4.0) which permits unrestricted noncommercial use, distribution, and reproduction in any medium, provided the original work is properly cited.
}

Articles can be freely viewed online at www.ppjonline.org. metabolism and reactive oxygen species scavenging activity.

Keywords : mechanosensation, plant immunity, priming, proteomics, sound vibration

Handling Editor : Ryu, Choong-Min

Environmental stresses affect the growth, development, and productivity of crops and vegetables across the globe. Environmental stress can be biotic or abiotic in nature. Biotic factors include pathogens, insects and other microorganisms that exist in the ecological milieu of plants, whereas abiotic factors constitute, temperature, light intensity, and other parameters. Making plants resistant to diverse forms of environmental stress is an ideal aim of an agricultural scientist. To enhance the plant disease resistance, two widely used techniques are (1) conventional breeding and (2) developing genetically modified crops; both are time-consuming and expensive. Nowadays, 'priming' or 'hardening' approaches are gaining attention, as they hold promise to offer an alternative strategy for sustainable agriculture. Priming is a biological phenomenon which boosts plant's basal defense responses after being subjected to a mild stress or some chemical exposure (Balmer et al., 2015). It was hypothesized that stress priming can be imprinted as molecular-'memory' within a plant cell, either as epigenetic marks or in the form of defense metabolites and proteins (Pastor et al., 2013). Consequently, the primed plants display strong defense response under the possible future stress scenarios.

Various agents can be used to prime seeds or intact plants. For instance, salicylic acid (SA), methyl-jasmonate, azelaic acid, $\beta$-aminobutyric acid, and hydrogen peroxide $\left(\mathrm{H}_{2} \mathrm{O}_{2}\right)$ are well-known priming agents (Balmer et al., 
2015). In addition, an effective form of plant stress priming can be mechanical stimuli; mechanical; repetitive exposure of mechanical stimuli (e.g., touch, wind, brushing, and pressing) can bolster plants' structural strength, promote resilience to insect attack and pathogen infection, as well as facilitate stress tolerance (Li and Gong, 2011). However, the majority of plants are slow in response, and morphological changes are observed after a long time of repeated mechanical stimulation (Chehab et al., 2011). Alteration in plant growth and development upon mechanical perturbation has been termed as thigmomorphogenesis (Chehab et al., 2011). Among various forms of mechanical stimuli, touch stimulus evoked plant responses are the most-studied one at the molecular level (Braam, 2005). Repetitive touch treatments given to Arabidopsis leaves results in enhanced resistance against Botrytis cinerea in a jasmonic acid-dependent manner (Chehab et al., 2012). Mechanical-priming has also been used for sustainable agronomic purpose. For instance, 'Mugifumi' is a beneficial farm work practiced in Japan for hardening and increasing the yields of wheat and barley through physical compression (Iida, 2014). Taken together, it is suggestive that mechanical stimuli can act as a priming agent, which has a potential to offer an easy, inexpensive, and sustainable approach for crop protection.

From the sound of wind gusts to the vibrations of caterpillar chewing, plants are often exposed to various forms of sound vibration (SV). Being a mechanical pressure wave, $\mathrm{SV}$ can induce various physiological changes in plants. In earlier studies, a number of SV-induced cellular responses were noticed, which includes calcium spiking, reactive oxygen species (ROS) generation, enhanced antioxidant enzyme activities, changed physical state of membrane lipids and proteins, increased transcription, translation, and effects on cell cycle (Mishra et al., 2016). Moreover, a recent finding establishes the priming potential of SV; pre-exposure to caterpillar-chewing vibration can induce a chemical defense response in Arabidopsis by virtue of accumulating glucosinolates and anthocyanin (Appel and Cocroft, 2014). SV-mediated disease resistance was noticed in strawberry plants as well (Qi et al., 2010). In a preliminary study, exposure to SV was noted to induce drought tolerance in Arabidopsis (López-Ribera and Vicient, 2017). Taken together, aforementioned studies indicate that SV has the potential to generate priming effects in plants; however, the molecular mechanisms that govern such response remain elusive. Therefore, it is important to elucidate the underlying molecular mechanisms for SV-mediated priming and improved stress tolerance. In this regard, our previous study revealed that $1,000 \mathrm{~Hz} \mathrm{SV}$ at $100 \mathrm{~dB}$ can enhance Arabidopsis resistance against Botrytis cinerea (Choi et al., 2017). Additionally, the transcriptomic and hormone analyses revealed that SV-treated Arabidopsis plants delayed the infection process against Botrytis through SAand systemic acquired resistance-mediated pathways (Choi et al., 2017).

Active cellular defense mechanism relies on the effective production of defense metabolites and hormones. Further, the distribution of such defense molecules towards the sites of infection is pivotal for survival of the host. To achieve this, plants need to channelize their resources for effective production and redistribution of energy. It is pertinent to mention that in our previous work many differentially expressed genes related to primary and secondary metabolism were identified in the SV-treated Arabidopsis during Botrytis infection (Choi et al., 2017). However, gene expression states could not always correlate with the protein expression. Thus, to gain better understanding at the protein level, SV-treated and SV-untreated Arabidopsis plants were inoculated with Botrytis spores to compare the proteome states of infected SV-treated plants (henceforth referred to as 'SV-infected') to the infected SV-untreated plants (henceforth referred to as 'non-SV-infected'). In the end, we are proposing a model to summarize the effects of SV pre-treatment in defense response in plant cells. Fundamentally, new knowledge about the proteomics level can facilitate plant acoustic research and plant stress acclimation, which is likely to be translated into agronomic benefits for priming crop plants.

\section{Materials and Methods}

Plant growth conditions and SV treatment. Arabidopsis thaliana (Columbia-0) plants were treated with SV and inoculated with Botrytis cinerea as previously described by Choi et al. (Choi et al., 2017). Arabidopsis plants were grown under continuous light $\left(150 \mu \mathrm{mol} / \mathrm{m}^{2} / \mathrm{s}\right)$ in a growth room at $23 \pm 1{ }^{\circ} \mathrm{C}$. Fourteen-day-old plants were exposed to the single frequency SV $(1,000 \mathrm{~Hz}$ at $100 \mathrm{~dB})$ in a specialized sound-proof chamber daily $3 \mathrm{~h}$ for 10 days. Similarly, non-SV treated plants (i.e., control samples in the present study) were also kept in the sound-proof chamber without $\mathrm{SV}$ exposure. After 10 days, both SV-treated and non-SV treated plants were inoculated with Botrytis cinerea spores (in potato dextrose broth, $5 \times 10^{5}$ spores $/ \mathrm{ml}$ ). Subsequently, $\mathrm{SV}$-infected (i.e., SV-treated plants carrying Botrytis infection) and non-SV-infected (i.e., non-SV treated plants carrying Botrytis infection) plants were covered with a transparent lid to maintain humidity and were moved to the growth room. Infected rosette samples were harvested at various time points $(12,24,48$, and 72 hour post inocula- 


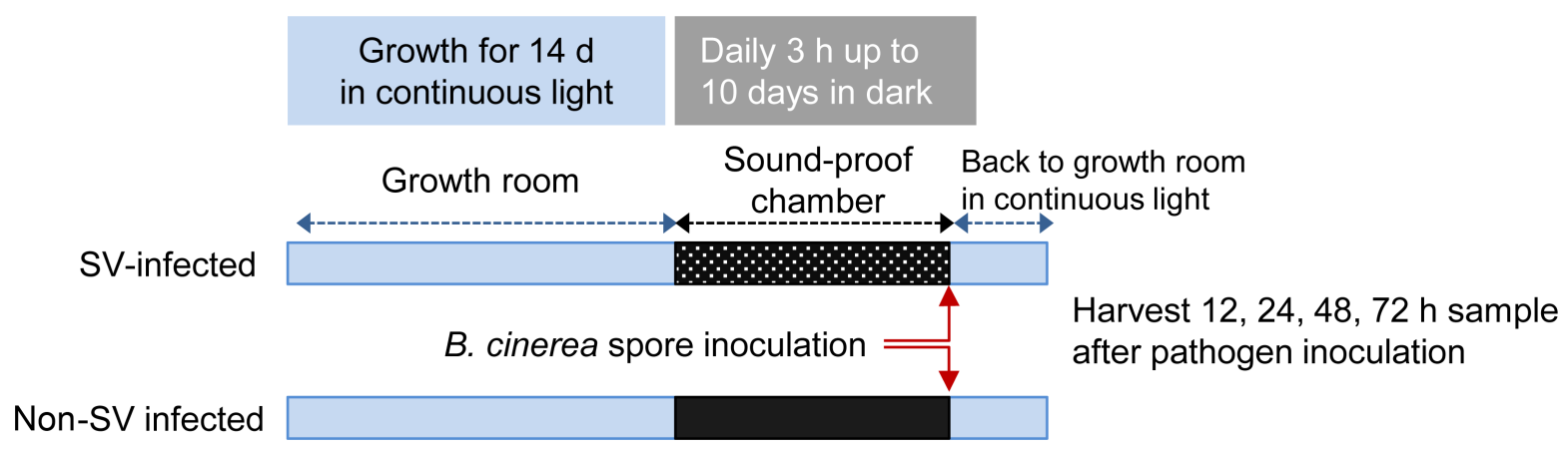

$1000 \mathrm{~Hz}$ at $100 \mathrm{~dB}$

Without SV

Fig. 1. Schematic representation of experimental strategy. The 14-day-old plants were exposed to 1,000 Hz sound vibration (SV) at 100 $\mathrm{dB}$ amplitude for daily $3 \mathrm{~h}$ up to 10 days in a specialized sound-proof chamber without light. Similarly, non-SV treated plants were also kept in the sound-proof chamber (in darkness) without SV exposure. After 10 days, both SV-treated and non-SV treated plants were inoculated with Botrytis cinerea spores. After pathogen inoculation, SV-infected and non-SV-infected plants were transferred back to the growth room. Infected rosette samples were harvested at 12, 24, 48, and 72 hour post inoculation (hpi).

tion [hpi]) in liquid nitrogen for proteomic and antioxidant enzyme assay analyses. Three biological replications were used for proteomic analysis and antioxidant enzyme assays. For a better representation, a schematic view of SV treatment method, pathogen inoculation, and sample harvesting time is shown in Fig. 1.

Proteomic profiling using two-dimensional gel electrophoresis (2-DE). Total protein was isolated from $\mathrm{Ara}$ bidopsis rosette leaves $(5 \mathrm{~g})$ and proteomic analysis was performed as previously described by Kwon et al. (2016). Total soluble proteins were quantified using the 2D-Quant kit (Amersham Biosciences Europe GmbH, Freiburg, Germany) and stored at $-70^{\circ} \mathrm{C}$ until 2-DE analysis. Later, 2-DE was carried out by PROTEAN IEF cell (Bio-Rad, Bio-Rad Laboratories GmbH, Munich, Germany) for the first-dimensional isoelectric focusing using the immobilized strips (17 cm, pH 5-8, Bio-Rad), and by Protean Xi-II Cell system (Bio-Rad) for the second-dimensional sodium dodecyl sulfate polyacrylamide gel electrophoresis. After silver staining, gel images were acquired by using a GS800 Imaging Densitometer (Bio-Rad) and analyzed using PDQuest version 7.2.0 software (Bio-Rad). All experiments were repeated three times and the volume of each spot was detected and normalized to a relative density. Proteins showing statistically significant difference $(P<$ 0.05 , fold change $>1.5$ ) between SV-infected and non-SVinfected plants during pathogen infection were selected for identification. For protein identification, differential protein spots visualized in the gel were excised and were subjected to in-gel digestion as described previously (Kwon et al.,
2010). Protein identification was performed through matrix assisted laser desorption ionization-time of flight mass spectrometry (MALDI-TOF/TOF MS) using ABI 4800 Plus TOF-TOF Mass Spectrometer (Applied Biosystems, Framingham, MA, USA). A total of 42 proteins were selected, of which, peptide mass tolerance and fragment mass tolerance were fixed at $100 \mathrm{ppm}$. High confidence interval showed statistically reliable search scores (greater than 95\% confidence) corresponding to protein's experimental isoelectric point $(p l)$ and molecular weight (MW). Finally, the differentially expressed proteins were classified into seven groups according to their attributes, using UniProt Knowledgebase (UniProtKB) and The Plant Proteome Database (PPDB).

Analysis of antioxidant enzyme activities. Antioxidant activities of five different enzymes were measured as mentioned previously (Kwon et al., 2010). Arabidopsis rosette leaves were ground into a fine powder in liquid nitrogen. The ground powder was mixed with $50 \mathrm{mM}$ potassium phosphate buffer ( $\mathrm{pH} 7.0$ ) and centrifuged at 9,100 $\times g$ for $20 \mathrm{~min}$. Then the supernatants were collected for the estimation of the enzyme activities. Superoxide dismutase (SOD; EC 1.15.1.1) activity was measured based on the generation of superoxide radical by xanthine and xanthine oxidase, which produced red formazan dye upon reaction with 2-(4-iodophenyl)-3-(4-nitrophenyl)-5-phenyl-2Htetrazolium. For ascorbate peroxidase (APX; EC 1.11.1.11) activity, reduction of ascorbate concentration was determined from decrease in the absorbance at $290 \mathrm{~nm}$ with extinction coefficient of $2.8 / \mathrm{mM} / \mathrm{cm}$. Glutathione reductase 
(GR; EC 1.6.4.2) activity was measured as mentioned previously (Kwon et al., 2010). For catalase (CAT; EC 1.11.1.6) activity, the initial rate of disappearance of $\mathrm{H}_{2} \mathrm{O}_{2}$ was measured by decline in absorbance at $240 \mathrm{~nm}$ with the extinction coefficient of $40 / \mathrm{mM} / \mathrm{cm}$. Dehydroascorbate reductase (DHAR; EC 1.8.5.4) activity was examined based on the increase of absorbance at $290 \mathrm{~nm}$ resulting from the conversion of dehydroascorbate to ascorbate. Finally, mean values of three replicates were calculated and plotted in graph with standard errors.

\section{Results}

SV treatment with $1,000 \mathrm{~Hz}$ alters proteomic profiles in $A$. thaliana during $B$. cinerea infection. In our previous study, we observed significant differences in disease level between SV-infected and non-SV-infected plants at 72 hpi, i.e., non-SV-infected plants had more senescent leaves than SV-infected plants (Choi et al., 2017). We observed similar results in the present study. Therefore, in this study, whole rosette samples were harvested at various time points until $72 \mathrm{hpi}$. The protein samples for 2-DE analysis were isolated from Botrytis-infected Arabidopsis rosette leaves (i.e., SV-infected or non-SV-infected plants) at different time points $(12,24,48$, and $72 \mathrm{hpi})$. Consequently, about 42 differentially expressed protein spots (intensity fold change $>1.5$ ) were identified between SV-infected and non-SV-infected plants during disease progression (Fig. 2). The entire list of proteins with molecular weights, isoelectric points, peptide hit, score, and identified peptide sequences are available in Table 1 and Supplementary Table 1. Alterations in the protein expression in the SVinfected Arabidopsis plants compared to non-SV-infected plants are displayed as color gradients in a heat map (Fig. 3). Based on their attributes, we classified the differentially expressed proteins into following groups. Mapman functional annotations of the proteins are available in Table 1.

Antioxidant protein levels. Several antioxidant enzymes were upregulated in the SV-infected plants compared to non-SV-infected plants. These proteins were identified as, peroxiredoxin (spots 2 and 14), APX (spot 20), SOD (spot 23), and monodehydroascorbate reductase (spot 64). Highest upregulation was found in 2-cys peroxiredoxin BAS1 at 12 hpi. Interestingly, glutathione S-transferase (spots 17 and 21) which plays an important role in redox homeostasis, was also upregulated in the SV-infected plants.

Proteins involved in energy metabolism. In response to pathogen infection, high expression of various subunits of
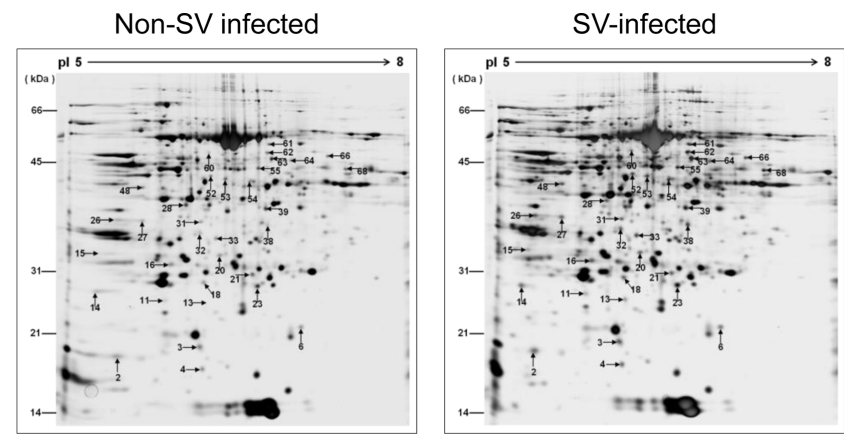

12 hpi
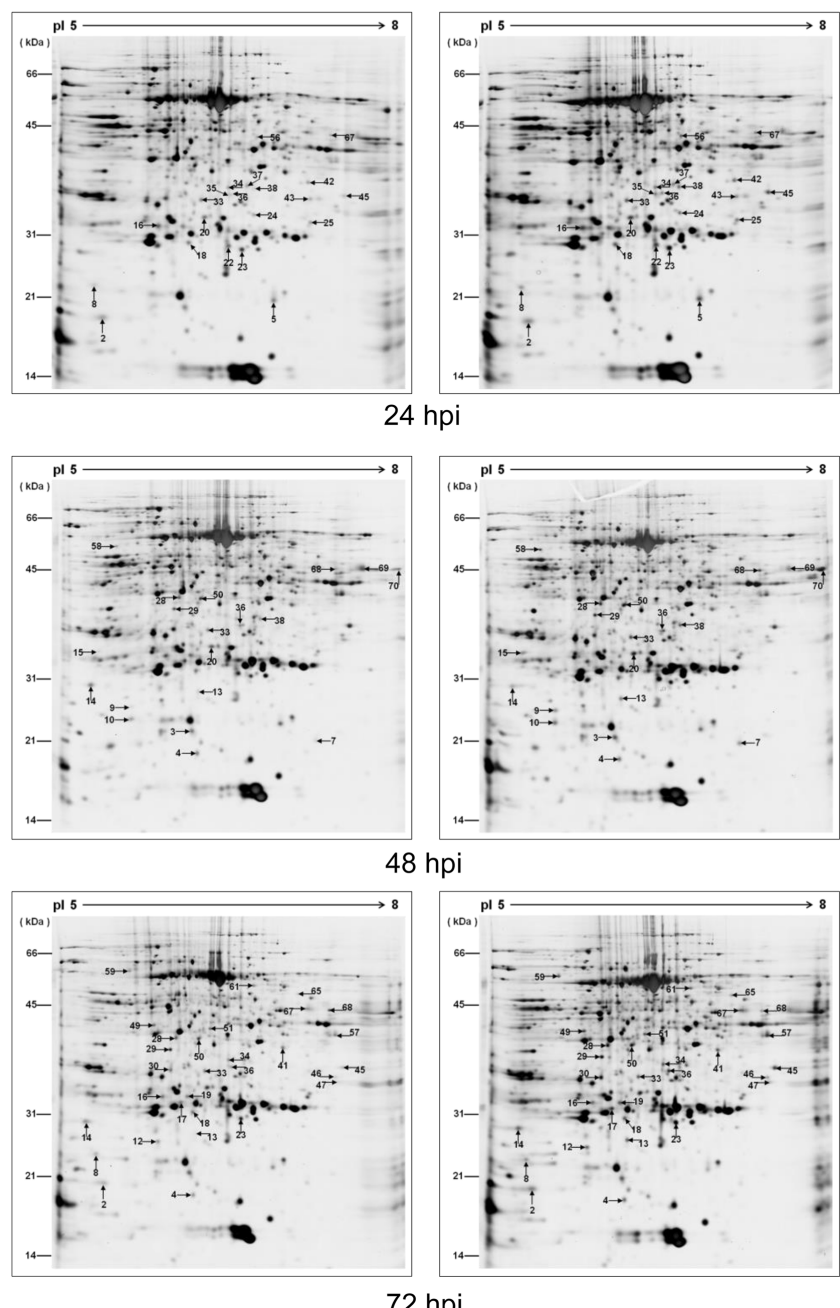

$72 \mathrm{hpi}$

Fig. 2. Proteomic profiling of sound vibration (SV)-infected and non-SV-infected Arabidopsis plants that carry Botrytis infection, using two-dimensional electrophoresis. Plants were treated with $1,000 \mathrm{~Hz}$ sound vibration at $100 \mathrm{~dB}$. The time $(12,24,48$, and 72) indicates hour post $B$. cinerea infection (hpi).

ATP synthase (spots 8, 13, 15, and 59) was observed in the SV-infected plants relative to non-SV-infected plants. Among them, highest upregulation was observed for ATP synthase subunit $\delta$ at 48 and 72 hpi. Besides this, enhanced 


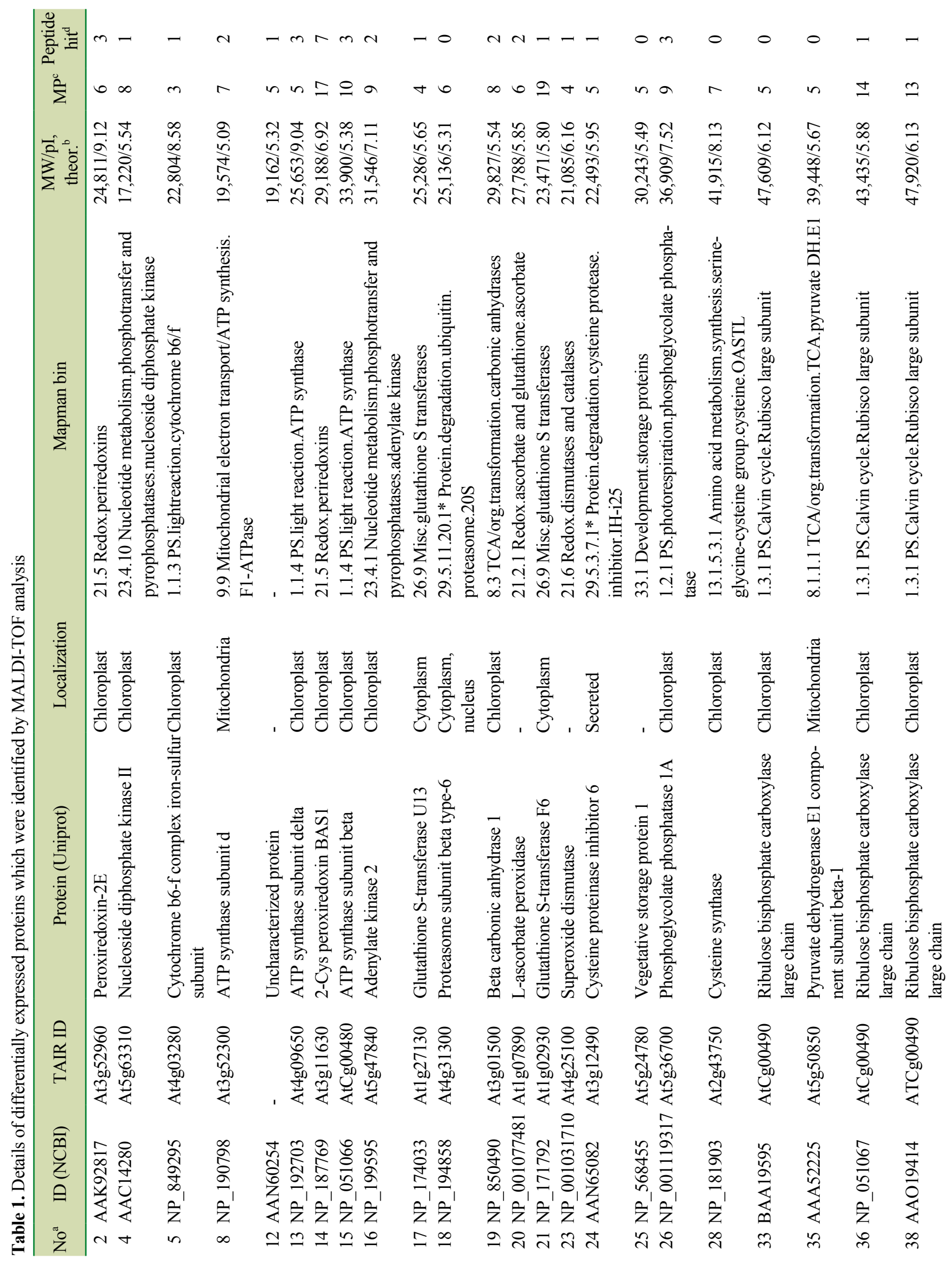




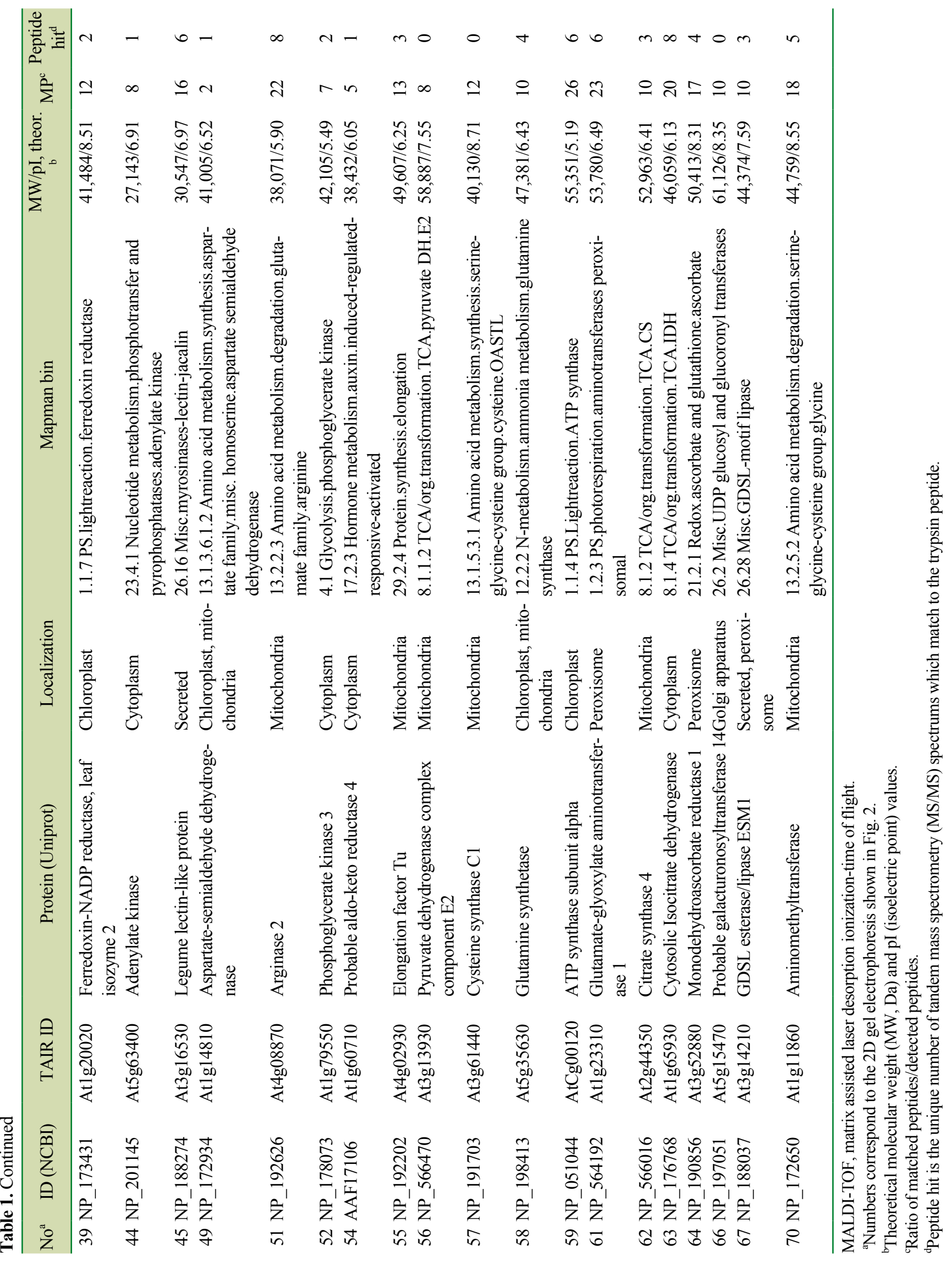


ID

\begin{tabular}{|c|}
\hline AAK92817 \\
\hline AAC 14280 \\
\hline NP_849295 \\
\hline NP_190798 \\
\hline AAN̄ 60254 \\
\hline NP_192703 \\
\hline NP_187769 \\
\hline NP_051066 \\
\hline NP_199595 \\
\hline NP_174033 \\
\hline NP_194858 \\
\hline NP_850490 \\
\hline NP_001077481 \\
\hline NP_171792 \\
\hline NP_001031710 \\
\hline AAN̄ 65082 \\
\hline NP_568455 \\
\hline NP_001119317 \\
\hline NP_181903 \\
\hline BAĀ19595 \\
\hline AAA52225 \\
\hline NP_051067 \\
\hline AAŌ19414 \\
\hline NP_173431 \\
\hline NP_201145 \\
\hline NP_188274 \\
\hline NP_172934 \\
\hline NP_192626 \\
\hline NP_178073 \\
\hline AAF17106 \\
\hline NP_192202 \\
\hline NP_566470 \\
\hline NP_191703 \\
\hline NP_198413 \\
\hline NP_051044 \\
\hline NP_564192 \\
\hline NP_566016 \\
\hline NP_176768 \\
\hline NP_190856 \\
\hline NP_197051 \\
\hline NP_188037 \\
\hline$N P \_172650$ \\
\hline
\end{tabular}

Spot no Protein (based on UniProtKB)

Peroxiredoxin-2E

Nucleoside diphosphate kinase ॥

Cytochrome b6-f complex iron-sulfur subunit

ATP synthase subunit $d$

Uncharacterized protein

ATP synthase subunit delta

2-Cys peroxiredoxin BAS1

ATP synthase subunit beta

Adenylate kinase 2

Glutathione S-transferase U13

Proteasome subunit beta type- 6

Beta Carbonic anhydrase 1

L-ascorbate peroxidase

Glutathione S-transferase F6

Superoxide dismutase

Cysteine proteinase inhibitor 6

Vegetative storage protein 1

2-phosphoglycolate phosphatase $1 \mathrm{~A}$

Cysteine synthase

Ribulose bisphosphate carboxylase $L$ chain

Pyruvate dehydrogenase E1

Ribulose bisphosphate carboxylase $L$ chain

Ribulose bisphosphate carboxylase $L$ chain

Ferredoxin-NADP reductase, leaf isozyme 2

Adenylate kinase

Legume lectin-like protein

Aspartate-semialdehyde dehydrogenase

Arginase 2

Phosphoglycerate kinase 3

Probable Aldo-keto reductase 4

Elongation factor Tu

Pyruvate dehydrogenase complex E2

Cysteine synthase $\mathrm{C} 1$

Glutamine synthetase

ATP synthase subunit alpha

Glutamate-glyoxylate aminotransferase 1

Citrate synthase 4

Isocitrate dehydrogenase

Monodehydroascorbate reductase 1

Probable galacturonosyltransferase 14

GDSL esterase/lipase ESM1

Aminomethyltransferase

\begin{tabular}{|c|c|c|c|}
\hline 2 & 24 & 48 & 72 \\
\hline T & $2.5^{\star \star \star *}$ & $1.6^{* *}$ & $2.4^{* *}$ \\
\hline $1^{* *}$ & $1.6^{*}$ & $2.4^{* * *}$ & $3.5^{* * *}$ \\
\hline $5^{* * *}$ & $1.9^{* * *}$ & $1.6^{* * *}$ & $1.9^{*}$ \\
\hline $3^{* *}$ & $2.5^{* * *}$ & $1.5^{\star *}$ & $1.8^{* * *}$ \\
\hline 18 & $1.5^{\star *}$ & $1.6^{* *}$ & $1.8^{* *}$ \\
\hline $4.5^{\star \star *}$ & $2.1^{* *}$ & $6^{* * *}$ & $5.3^{* * *}$ \\
\hline $4^{* * *}$ & $1.6^{* * *}$ & $1.6^{* * *}$ & $2.4^{* * *}$ \\
\hline $6^{* * *}$ & $1.5^{*}$ & $2.8^{* \star *}$ & $1.8^{* *}$ \\
\hline $7^{* * *}$ & $1.6^{* *}$ & $1.5^{* * *}$ & $1.6^{* * *}$ \\
\hline $9^{* * *}$ & $2.5^{\star * *}$ & $1.6^{* *}$ & $3.6^{* * *}$ \\
\hline $3.2^{* * *}$ & $2^{* *}$ & $2.1^{* * *}$ & $3^{* *}$ \\
\hline $1.5^{*}$ & $2.2^{* \star *}$ & $1.8^{* *}$ & $3.7^{* * *}$ \\
\hline $7^{* *}$ & $2.4^{* * *}$ & $2.4^{* * *}$ & $2^{* * *}$ \\
\hline $6^{* * *}$ & $1.5^{\star *}$ & $1.7^{* \star *}$ & $1.6^{* * *}$ \\
\hline $2^{* * *}$ & $2.4^{* * *}$ & $1.9^{* * *}$ & $2.1^{* * *}$ \\
\hline $3^{* * *}$ & $3.1^{* * *}$ & $2.3^{* *}$ & $2.1^{* *}$ \\
\hline $.2^{* *}$ & $2.2^{* \star *}$ & $2.8^{* * *}$ & $1.7^{* *}$ \\
\hline $4.8^{* * *}$ & $1.7^{* *}$ & $2.2^{* * *}$ & $2.3^{* * *}$ \\
\hline $1.5^{* *}$ & $1.9^{* *}$ & $2^{* *}$ & $3.1^{* * *}$ \\
\hline $2.8^{* * *}$ & $1.7^{* *}$ & $3.1^{* *}$ & $2.1^{* *}$ \\
\hline $4.3^{* *}$ & $7.5^{* * *}$ & $2.4^{* *}$ & $2.1^{* * *}$ \\
\hline $2.2^{* *}$ & $3.5^{* * *}$ & $1.8^{* * *}$ & $3.7^{* * *}$ \\
\hline $4.2^{* * *}$ & $3.7^{* *}$ & $2.2^{* * *}$ & $2.3^{* *}$ \\
\hline $2.1^{* \star *}$ & $1.9^{* * *}$ & $2.2^{* *}$ & $1.9^{* * *}$ \\
\hline $1.9^{* * *}$ & $1.7^{* * *}$ & $1.6^{* *}$ & $2.2^{* *}$ \\
\hline $2.2^{* *}$ & $4.8^{* * *}$ & $1.8^{* * *}$ & $5.4^{* * *}$ \\
\hline $1.7^{*}$ & $1.7^{* *}$ & $1.8^{* *}$ & $2.3^{* * *}$ \\
\hline $2^{* * *}$ & $1.8^{* *}$ & 1.6 & $1.8^{* * *}$ \\
\hline $2.5^{* * *}$ & $1.5^{* *}$ & $1.9^{* *}$ & $1.7^{* *}$ \\
\hline $2.9^{* \star *}$ & $2.6^{* *}$ & $1.9^{* *}$ & $2.2^{* *}$ \\
\hline $2.4^{* * *}$ & $2.3^{* * *}$ & $1.9^{* * *}$ & $2^{* *}$ \\
\hline $2.2^{* *}$ & $1.9^{* *}$ & $2.1^{* *}$ & $1.8^{* *}$ \\
\hline $1.7^{*}$ & $1.6^{\star *}$ & $2.1^{* * *}$ & $3.3^{* * *}$ \\
\hline $1.7^{* *}$ & $1.8^{* *}$ & $2.2^{* * *}$ & $2.1^{* * *}$ \\
\hline $1.4^{* *}$ & 1.8 & $1.6^{* *}$ & $3.7^{* * *}$ \\
\hline $2.1^{* * *}$ & $1.8^{* *}$ & $1.5^{* *}$ & $2.7^{* *}$ \\
\hline $1.9^{* * *}$ & $1.6^{* *}$ & $2^{* *}$ & $1.7^{* *}$ \\
\hline $2^{* * *}$ & $1.5^{\star * *}$ & $1.6^{* *}$ & $1.6^{* *}$ \\
\hline $3.6^{* *}$ & $2.2^{* * *}$ & $2^{*}$ & $2.1^{* *}$ \\
\hline $1.8^{* * *}$ & $1.7^{* *}$ & $1.8^{* *}$ & $1.8^{* *}$ \\
\hline $2.2^{* *}$ & $1.6^{* *}$ & $2^{* *}$ & $1.9^{* *}$ \\
\hline $1.7^{* * *}$ & $1.9^{* * *}$ & $3.3^{* * *}$ & $1.8^{* *}$ \\
\hline
\end{tabular}

Fig. 3. Heatmap of the differentially expressed proteins in the sound vibration (SV)-infected Arabidopsis thaliana. A total of 42 candidate proteins were selected, which were more than 1.5-fold induced (red) in the SV-infected plants when compared to the non-SVinfected plants. The time (12, 24, 48, and 72) indicates hour post inoculation of Botrytis spores. Values within the cells indicate the fold changes $(n=3)$. $P$-value ranges are marked by asterisks: ${ }^{* * *} P<0.01,{ }^{* *} 0.01<P<0.05,{ }^{*} P<0.1$. 'Spot no.' indicates the numbers corresponding to the 2D gel electrophoresis (shown in Fig. 2).

expression of two enzymes related to nucleotide metabolism was also seen, i.e., nucleoside diphosphate kinase (spot 4) and adenylate kinase (spots 16 and 44).

Proteins involved in photosynthesis. We were able to identify elevated expression of five photosynthetic proteins in the SV-infected plants. Among them, cytochrome b6-f complex iron-sulfur subunit (spot 5) and ferredoxin-NADP reductase (spot 39) take part in the light reaction, and ribulose bisphosphate carboxylase large chains (spots 33, 36, and 38) are involved in Calvin cycle. 
Glycolysis and tricarboxylic acid (TCA) cycle proteins. We observed high expression of six enzymes in the SVinfected plants which are involved in glycolysis and TCA cycle. These enzymes were carbonic anhydrase (spot 19), phosphoglycerate kinase (spot 52), citrate synthase (spot 62), isocitrate dehydrogenase (spot 63) and pyruvate dehydrogenase (spots 35 and 56). Among them, highest expression was observed for pyruvate dehydrogenase E1, especially at $24 \mathrm{hpi}$.

Proteins associated with amino acid metabolism. Enhanced expression of seven proteins that are involved in amino acid metabolism was seen in the SV-infected plants compared to non-SV-infected plants. These proteins were cysteine synthase (spots 28 and 57), aspartate-semialdehyde dehydrogenase (spot 49), arginase (spot 51), glutamine synthetase (spot 58), glutamate-glyoxylate aminotransferase (spot 61; GGAT1) and aminomethyltransferase (spot 70).

Changes in defense-related proteins. Four defenserelated proteins were upregulated in the SV-infected plants compared to non-SV-infected plants. These are vegetative storage protein (spot 25; VSP1), legume lectin-like protein (spot 45), GDSL esterase/lipase ESM1 (spot 67), and cysteine proteinase inhibitor (spot 24). Among them, the highest expression was observed for legume lectin-like protein at 24 and 72 hpi. LECTIN and VSP1 act as defense proteins against pathogens and predators (Liu et al., 2005; Peumans and van Damme, 1995). Cysteine proteinase inhibitor (also known as cystatins) has antifungal properties and also protects plants from pathogens and pests (Martinez et al., 2005). ESM1 catalyzes conversion of non-active glucosinolates into bio-active compounds, which play an important role in plant-pathogen and plant-herbivore interactions (Zhang et al., 2006). Blast search indicated that uncharacterized protein (spot 12) is homologous to pathogenesis-related protein (i.e., PR4) which positively regulates SA-mediated defense response in plants.

Miscellaneous. The proteins in this group are involved in diverse cellular functions. Increased expression of two proteins - proteasome subunit $\beta$-type 6 (spot 18) and translation elongation factor $\mathrm{Tu}$ (spot 55) - that are involved in protein metabolism was seen. Apart from this, phosphoglycolate phosphatase (spot 26) and GGAT1 - enzymes involved in photorespiration -were also noted to be upregulated in the SV-infected plants compared to non-SVinfected plants.
Gene ontology enrichment analysis of the di-erentially expressed proteins. The gene IDs of the differentially expressed proteins were used for the gene ontology (GO) analysis through DAVID bioinformatics resources. The list of genes and the details of the enrichment analysis $(P<0.05)$ of $3 \mathrm{GO}$ classes (biological process, molecular function, and cellular component) are available in Supplementary Table 2. Enrichment analysis indicates that upregulated proteins in the SV-infected plants are highly enriched with cysteine biosynthetic process (Fig. 4A). Interestingly, the majority of upregulated proteins are stromule-localized

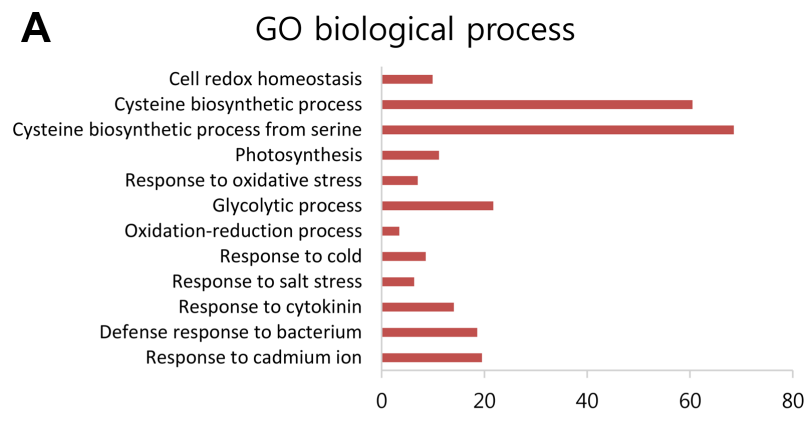

B

GO cellular compartment

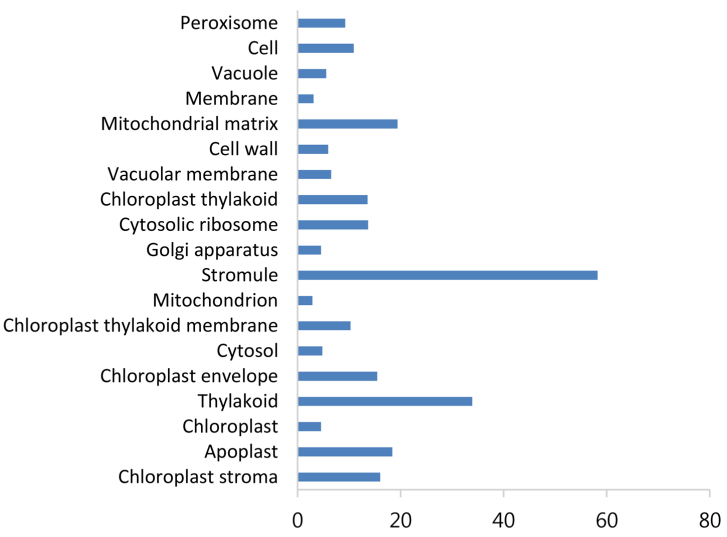

C GO molecular function

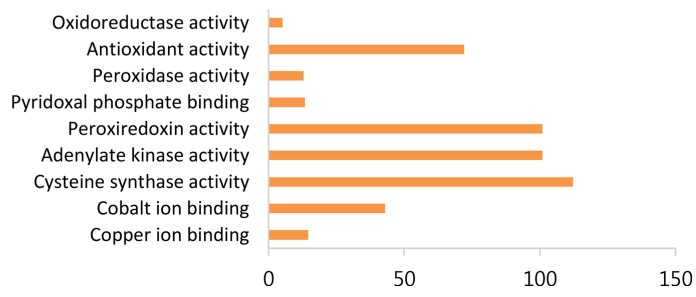

Fig. 4. Gene ontology (GO) enrichment analysis of differentially expressed proteins through DAVID bioinformatics recourses. The gene IDs of the differentially expressed proteins were used for the analysis. The enrichment analysis of $3 \mathrm{GO}$ classes (biological process, molecular function, and cellular component) were performed at $P<0.05$. 
(Fig. 4B). Stromule is a tubular extension of the plastid filled with stroma (Caplan et al., 2015). According to the GO molecular function, the upregulated proteins in the SVinfected plants are enriched with antioxidant and adenylate kinase activities (Fig. 4C).

Comparative analysis of proteomics and transcriptomics datasets in the context of primary metabolism. The present study indicates that the majority of the differentially expressed proteins are involved in the primary metabolism. Our previous GO analysis of transcriptomics data also revealed that differentially expressed genes in the SV-infected plants were enriched with various primary metabolic processes (Choi et al., 2017). For example, the upregulated genes at 12 hpi in the SV-infected plants were enriched with redox homeostasis (GO:0045454) function. Moreover, the upregulated genes at 24 hpi in the SVinfected plants were significantly enriched with photosynthesis (GO:0015979) and photosynthetic electron transport process (GO:0009767).
In addition to this, we performed a pathway enrichment analysis to compare the transcriptomics and proteomics datasets and identify the genes involved in primary metabolism. For this purpose, we used a group of genes from our previous study that was differentially expressed $(P<$ 0.05 and fold change $>1.5)$ in the SV-treated $(0$ hpi, i.e., pre-inoculation of Botrytis spore) and SV-infected (12 and 24 hpi) plants (Choi et al., 2017). Pathway enrichment analysis was performed through EXPath - a web tool which can identify the enriched Kyoto Encyclopedia of Genes and Genomes pathways of a group of genes (Chien et al., 2015). This analysis identified several genes that are involved in primary metabolic pathways (Supplementary Table 3). Twelve genes related to photosynthesis (pathway ID: 00195, 00196, 00710) were identified and a majority of them were upregulated in the SV-treated plants at preand post-inoculation. Notably, many of these genes encode photosystem I and II subunits, light-harvesting complex II chlorophyll $\mathrm{a} / \mathrm{b}$ binding protein, ferredoxin-NADP ${ }^{+}$ reductase, and ribulose bisphosphate carboxylase. Seven
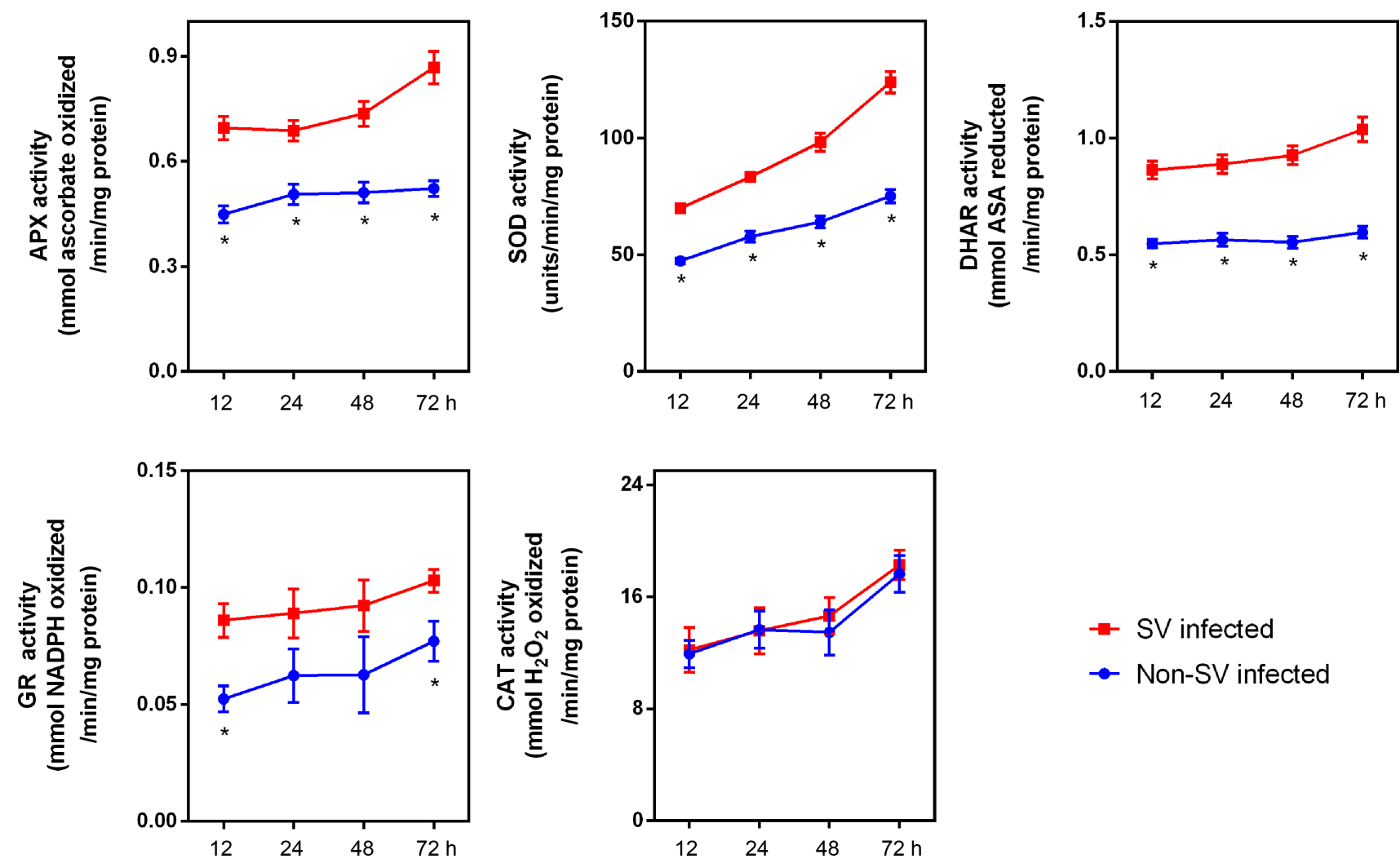

Fig. 5. Determination of antioxidant enzyme activities in the sound vibration (SV)-infected and non-SV-infected Arabidopsis thaliana. Enzyme activities of superoxide dismutase (SOD), ascorbate peroxidase (APX), dehydroascorbate reductase (DHAR), glutathione reductase (GR), and catalase (CAT) were measured in SV-infected (red) and non-SV-infected (blue) Arabidopsis plants. The time (12, 24, 48, and 72) indicates hour post inoculation of Botrytis spores. The data represent the mean of three replications with standard error. Asterisks indicate significant difference $(P<0.05)$ between non-SV-infected and SV-infected plants. 
genes related to glycolysis/gluconeogenesis and TCA cycle (pathway ID: 00010, 00020) were identified. Among them, triosephosphate isomerase, phosphoenolpyruvate carboxykinase, aldehyde dehydrogenase, pyruvate dehydrogenase, pyruvate kinase, and glyceraldehyde 3-phosphate dehydrogenase are the prominent ones. Interestingly, five genes that are involved in oxidative phosphorylation (pathway ID 00190) were upregulated in the SV-treated plants at pre-and post-inoculation. This group includes $\mathrm{H}^{+}$-transporting ATPase, NADH dehydrogenase, and pyrophosphorylase. Oxidative phosphorylation is the major ATP producing pathway in the cell. However, eight genes that are involved in amino acid biosynthesis (pathway ID 01230) were mainly downregulated in the SV-treated as well as SV-infected plants. Three genes that are involved in sulfur and cysteine/methionine metabolism (pathway ID 00920, 00270) were noted to be upregulated in the SVtreated plants at pre- and post-inoculation. Interestingly, two genes related to glucosinolate biosynthesis (pathway ID 00966) were noted to be upregulated in the SV-infected plants at 24 hpi. Glucosinolate biosynthesis is closely linked to the sulfur metabolism (Rausch and Wachter, 2005). On the other hand, eight glutathione S-transferase genes (pathway ID 00480), involved in redox homeostasis, were noted to be differentially expressed in the SV-infected plants at 12 and $24 \mathrm{hpi}$. By and large, the expression pattern of photosynthesis, respiration, and energy metabolismrelated proteins was noted to be in good correlation with transcriptomics results. However, sometimes comparison of transcriptomics and proteomics datasets does not show a good correlation due to the post-transcriptional regulation.

SV treatment with $1,000 \mathrm{~Hz}$ increases antioxidant enzyme activities in $A$. thaliana during $B$. cinerea infection. The proteomic analysis revealed enhanced accumulation of antioxidant enzymes in the SV-infected plants compared to non-SV-infected plants during disease progression. We hypothesized that SV treatment increases disease resistance through elevated antioxidant enzyme activities in the infected plants. To test this hypothesis, we measured the enzyme activities of five representative antioxidant enzymes (Fig. 5). The activity of APX which reduces $\mathrm{H}_{2} \mathrm{O}_{2}$ to $\mathrm{H}_{2} \mathrm{O}$ by utilizing ascorbate as a specific electron donor, was significantly increased in the SV-infected plants compared to non-SV-infected plants at all-time points. SOD activity, which catalyzes the dismutation of $\mathrm{O}_{2}^{-}$to $\mathrm{H}_{2} \mathrm{O}_{2}$, was also enhanced in the SV-infected plants. The activity of DHAR, which reduces dehydroascorbate to ascorbate using glutathione (GSH) as reductant, was maintained at higher level in the SV-infected plants than non-SV-infected plants. GR, which catalyzes the reduction of GSH, showed enhanced activity at 12 and 72 hpi in the SV-infected plants. However, no significant difference was detected in CAT activity, which decomposes $\mathrm{H}_{2} \mathrm{O}_{2}$ to $\mathrm{O}_{2}$ and $\mathrm{H}_{2} \mathrm{O}$. These observations revealed that activities of antioxidant enzymes were enhanced in the SV-treated plants during pathogen infection.

\section{Discussion}

Previously it was observed that SV pre-treatment elevates the defense response of Arabidopsis plants against Botrytis cinerea (Choi et al., 2017). Moreover, studies at the molecular level identified the increased levels of SA and defense-related transcripts (e.g., flavonoid and GSH biosynthesis, and cell wall biosynthesis/organization) in the SV-treated plants during pathogen infection (Choi et al., 2017). Taken together, it is clear that SV-treated plants can modulate their metabolism more swiftly than non-SV treated plants during pathogen infection. During pathogen infection, plants require more energy for synthesizing defense molecules and also for their transport to the infected sites. Energy demands of the host cells under pathogen attack are catered by the production of ATPs mainly from the respiratory pathway, i.e., mitochondrial electron transport chain. Our data revealed an increase in the level of respiratory enzymes (i.e., glycolytic and TCA cycle) in the SV-infected plants (Fig. 3). Additionally, the level of mitochondrial ATP synthase enzyme (spot 8) in the SV-infected plants was also increased. It is known that SV itself can induce $\mathrm{H}^{+}$-ATPase activity and ATP content in plant cells (Xiaocheng et al., 2003; Yi et al., 2003). For example, synthetic SV $(1,000 \mathrm{~Hz}, 100 \mathrm{~dB})$ was found to induce the $\mathrm{H}^{+}$-ATPase activity in chrysanthemum roots and callus (Wang et al., 2002; Yi et al., 2003). The efficient energy metabolism in the SV-treated plants may generate a robust defense response during the course of pathogen infection which delays disease manifestation.

Reduction in the rates of photosynthetic activity is a characteristic of infected plant tissues; however, photosynthetic rates can also be enhanced in the non-infected systemic tissues (Bolton, 2009). Increased photosynthetic rates could support plant defense requirements by producing energy, sugars, and reducing equivalents (Bolton, 2009). In our experiments, we observed enhanced levels of photosynthetic enzymes and chloroplastic ATPase in the SV-infected plants (Fig. 3). This phenomenon may occur due to the presence of more non-infected green leaves in the SV-infected plants than the non-SV-infected plants. Corroboratively, our previous report showed more senes- 
cent leaves in the non-SV-infected plants compared to SVinfected plants at $72 \mathrm{hpi}$ (Choi et al., 2017). On the other hand, reinforcement of the cell wall is a part of the plant defense strategy against invading pathogens (Bellincampi et al., 2014). Hence, elevated photosynthetic enzymes in the SV-infected plants may increase production of cell wall polysaccharides for cell wall thickening in the infected tissues. Corroboratively, our previous studies identified the increased levels of cell wall biosynthesis/organizing transcripts (e.g., TCH4) in the SV-infected plants at 24 hpi (Choi et al., 2017). In the future, a detailed study is needed to establish a direct role of photosynthesis in the SV-infected plants during disease progression.

Redox signaling plays an important role in plant defense. Increased level of ROS activates the hypersensitive cell death in infected plants, which exterminates invading biotrophs (van Kan, 2006). However, redox signaling is quite complex in the plant-necrotrophs interaction. Mycotoxins produced by the necrotrophic fungus together with elevated ROS kills the plant cells; that leads to susceptibility (van Kan, 2006). Consequently, plants upregulate their antioxidant enzymes to neutralize the ROS level. Previously it was observed that resistant plants produce more antioxidant enzymes during Botrytis infection compared to susceptible plants (Wan et al., 2015). Our proteomic analysis displayed increase in the expression of several antioxidant enzymes in the SV-infected plants (Fig. 3). Corroboratively, antioxidant enzyme assays revealed the increased activity of APX, SOD, DHAR, and GR (Fig. 5). SV itself can induce the expression of antioxidant enzymes and their activities in plants (Ghosh et al., 2016; Wei et al., 2012). It has been reported that $1,000 \mathrm{~Hz}$ SV with $100 \mathrm{~dB}$ intensity can induce the antioxidant activities in chrysanthemum seedlings and different organs of Dendrobium candidum (Li et al., 2008; Xiujuan et al., 2003). In addition to this, increased activities of antioxidant enzymes by ultrasound treatment was also noticed in Dendrobium officinale and suspensioncultured hazel cells (Safari et al., 2013; Wei et al., 2012). These results support the notion that SV-infected plants can neutralize ROS more efficiently than the non-SV-infected plants during disease progression.

Besides supporting cellular energy demands, several previous reports showed a more direct role of primary metabolism in plant defense responses. For example, hexokinase 1 (AtHXK1)-dependent activation of Arabidopsis $P R$ genes (PR-1 and $P R-5)$ by glucose was previously reported (Xiao et al., 2000). Hexokinase enzyme converts glucose to glucose-6-P and plays an important role in the glucose metabolic pathway. It has also been reported that the soluble sugars like glucose, fructose, and sucrose can induce the expression of $P R$ genes (i.e., $P A R-l, P R-Q$ ) in leaf discs of tobacco plants (Herbers et al., 1996). In addition to these, multiple studies indicate the roles of sugars and sugar-like compounds in plant immunity and activation of various defense genes (Bolouri Moghaddam and van den Ende, 2012). On the other hand, glycolate oxidase that coverts glycolate into glyoxylate during photorespiration also plays an important role in plant defense process. It has been noted that the expression of defense-related genes can be reduced in two Arabidopsis gox mutants (Atgox3 and Athaox2) after inoculation with $P$. syringae (Rojas et al., 2012). Alterations in amino acid metabolism also influence plant defense responses. Arabidopsis lht l (lysine histidine transporter 1) mutant that constitutively expresses $P R 1$ and has reduced contents of glutamine, alanine, and proline, showed enhanced resistance against diverse fungal and bacterial pathogens (Liu et al., 2010). The catabolism of lysine produces a non-protein amino acid-pipecolic acid (Pip) - that acts as an important immune signal and upregulates PRI expression in Arabidopsis (Bernsdorff et al., 2016). Taken together, it is clear that the primary metabolism has significant influences on defense gene expression. Therefore, we can hypothesize that the changes in primary metabolism ultimately induce the biosynthesis of defense proteins and metabolites in the infected plants. Our proteomics analysis identified increased accumulation of various defense proteins (i.e., lectin, VSP1, cystatins, and ESM1) in the SV-infected plants (Fig. 3). This observation is corroborated by our previous finding, where elevated levels of lectin and VSP1 transcripts in the SV-infected plants were observed (Choi et al., 2017). Amino acid, especially cysteine (Cys) metabolism, plays a pivotal role in the synthesis of plant defense molecules. We observed elevated levels of Cys biosynthesis enzymes in the SV-infected plants during disease progression (Fig. 3). Moreover, the upregulated proteins in the SV-infected plants are enriched with cysteine synthase activity (Fig. 4C). Also, Cys serves as a precursor for the synthesis of various sulfur containing defense molecules like glucosinolates and camalexin (Rausch and Wachter, 2005). In our earlier work, we observed elevated levels of CYP71A13 (involved in camalexin biosynthesis) and MYB29 (involved in glucosinolate biosynthesis) transcripts in the SV-infected plants at 12 to 24 hpi (Choi et al., 2017). Thus, efficient biosynthesis of defense molecules via sulfur metabolism might induce the observed defense responses in the SV-infected plants.

Based on our results, a model is forwarded to depict the effect of SV on plant defense response (Fig. 6). However, it is still unknown how SV sensitize plant cells. The roles of membrane-bound mechanosensors (i.e., mechanosen- 


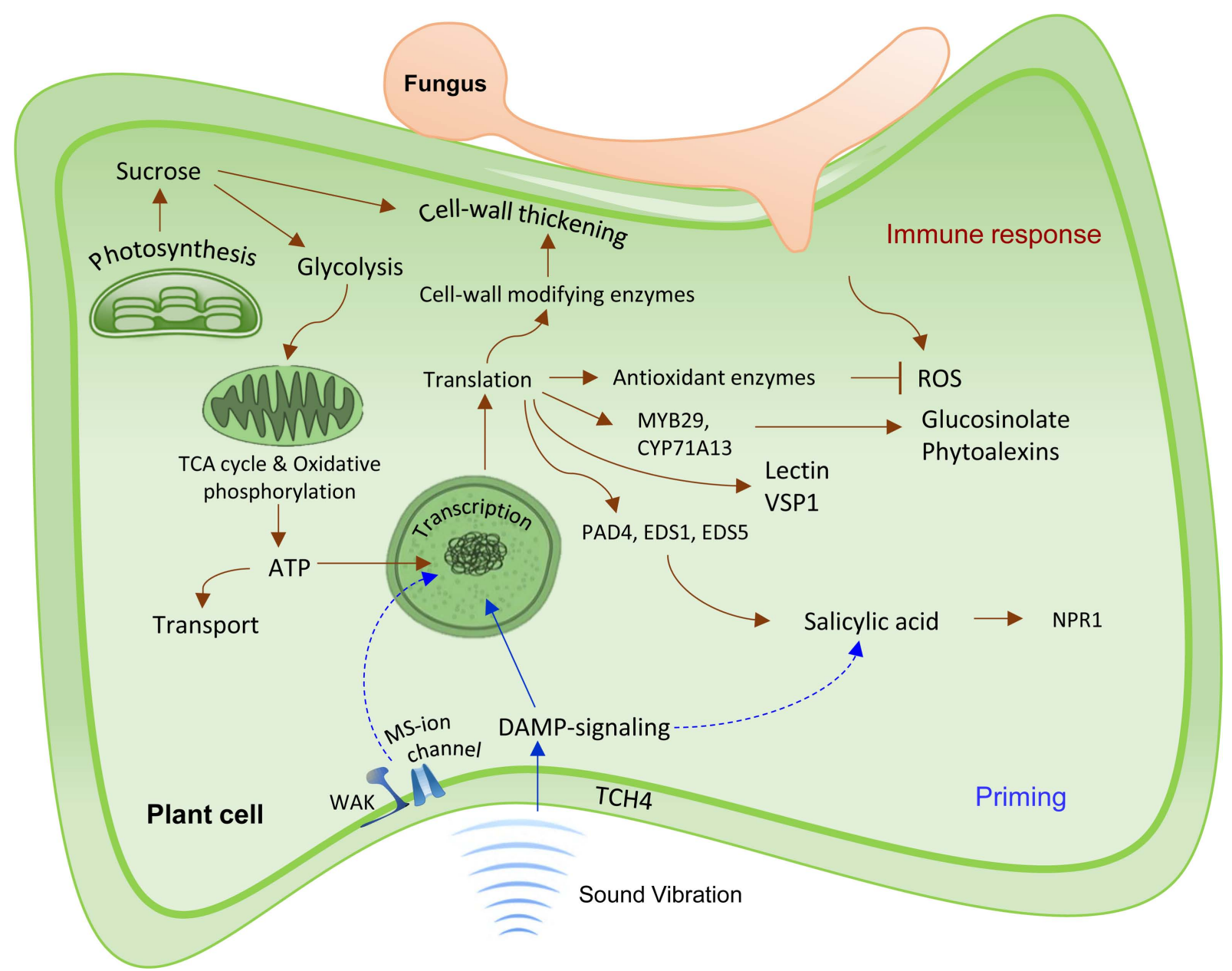

Fig. 6. Hypothetical model showing the effects of sound vibration pre-treatment in defense response in plant cells. Pointed arrows indicate activation and blunt arrows indicate repression. ROS, reactive oxygen species; TCA, tricarboxylic acid; DAMP, damage-associated molecular patterns.

sitive ion channels and wall-associated kinase) in plant mechanosensation have been hypothesized previously (Monshausen and Haswell, 2013). These mechanosensors may play important roles in SV perception as well (Mishra et al., 2016). Previously it was observed that SV treatment alters the expression of mechanosensitive ion channels in Arabidopsis (Ghosh et al., 2017). Additionally, SV-regulated cell wall modifying enzyme (e.g., TCH4) may activate damage-associated molecular patterns-mediated signaling which could trigger the accumulation of SA (Choi et al., 2017). Moreover, exposure to SV can alter physiological states (e.g., electrolyte leakage and photosynthesis) of plants (Ghosh et al., 2017). Such physiological and molecular adjustments prime the plants in such a way that the application of subsequent biotic stress generates efficient and sturdy defense responses. Invading pathogens generate ROS in host cells which triggers the defense response of plants. Consequently, it elevates the primary metabolism (e.g., glycolysis, TCA cycle, and energy metabolism) of infected cells, which facilitates the production of SA, defense metabolites, and proteins in the SV-infected plants. For this purpose, SV-priming upregulates several defense-related genes (PAD4, EDS1, EDS5, NPR1, MYB29, and CYP71A13) (Choi et al., 2017). Similarly, as a part of defense strategy, upregulation of cell wall modifying enzymes and antioxidant enzyme activities facilitate the cell wall reinforcement and ROS scavenging ability, respectively. All these improved molecular and physiological phenomena enhance the defense responses of the SV-infected plants. Collectively, our results indicate that SV pre-treatment can induce the defense responses in plants. However, a detailed mechanistic investigation is required in future where key characteristics of defense priming (e.g., memory, fitness costs, performance, and broad-spectrum activity) need to be analyzed (Martinez-Medina et al., 2016). Further research on plant interaction with SV has the potential to open the 
doors for a novel green technology, namely, stress priming via SV to make crop plants more resilient.

\section{Acknowledgments}

This work was supported by the 2016 Yeungnam University Research Grant.

\section{Electronic Supplementary Material}

Supplementary materials are available at The Plant Pathology Journal website (http://www.ppjonline.org/).

\section{References}

Appel, H. M. and Cocroft, R. B. 2014. Plants respond to leaf vibrations caused by insect herbivore chewing. Oecologia 175:1257-1266.

Balmer, A., Pastor, V., Gamir, J., Flors, V. and Mauch-Mani, B. 2015. The 'prime-ome': towards a holistic approach to priming. Trends Plant Sci. 20:443-452.

Bellincampi, D., Cervone, F. and Lionetti, V. 2014. Plant cell wall dynamics and wall-related susceptibility in plant-pathogen interactions. Front. Plant Sci. 5:228.

Bernsdorff, F., Döring, A. C., Gruner, K., Schuck, S., Bräutigam, A. and Zeier, J. 2016. Pipecolic acid orchestrates plant systemic acquired resistance and defense priming via salicylic acid-dependent and -independent pathways. Plant Cell 28:102-129.

Bolouri Moghaddam, M. R. and van den Ende, W. 2012. Sugars and plant innate immunity. J. Exp. Bot. 63:3989-3998.

Bolton, M. D. 2009. Primary metabolism and plant defense: fuel for the fire. Mol. Plant-Microbe Interact. 22:487-497.

Braam, J. 2005. In touch: plant responses to mechanical stimuli. New Phytol. 165:373-389.

Caplan, J. L., Kumar, A. S., Park, E., Padmanabhan, M. S., Hoban, K., Modla, S., Czymmek, K. and Dinesh-Kumar, S. P. 2015. Chloroplast stromules function during innate immunity. Dev. Cell 34:45-57.

Chehab, E. W., Wang, Y. and Braam, J. 2011. Mechanical force responses of plant cells and plants. In: Mechanical integration of plant cells and plants, ed. by P. Wojtaszek, pp. 173-194. Springer-Verlag Berlin Heidelberg, Heidelberg, Germany.

Chehab, E. W., Yao, C., Henderson, Z., Kim, S. and Braam, J. 2012. Arabidopsis touch-induced morphogenesis is jasmonate mediated and protects against pests. Curr. Biol. 22:701706.

Chien, C.-H., Chow, C.-N., Wu, N.-Y., Chiang-Hsieh, Y.-F., Hou, P.-F. and Chang, W.-C. 2015. EXPath: a database of comparative expression analysis inferring metabolic pathways for plants. BMC Genomics 16 Suppl 2:S6.

Choi, B., Ghosh, R., Gururani, M. A., Shanmugam, G., Jeon, J., Kim, J., Park, S.-C., Jeong, M.-J., Han, K.-H., Bae, D.-W. and Bae, H. 2017. Positive regulatory role of sound vibration treatment in Arabidopsis thaliana against Botrytis cinerea infection. Sci. Rep. 7:2527.

Ghosh, R., Gururani, M. A., Ponpandian, L. N., Mishra, R. C., Park, S.-C., Jeong, M.-J. and Bae, H. 2017. Expression analysis of sound vibration-regulated genes by touch treatment in Arabidopsis. Front. Plant Sci. 8:100.

Ghosh, R., Mishra, R. C., Choi, B., Kwon, Y. S., Bae, D. W., Park, S.-C., Jeong, M.-J. and Bae, H. 2016. Exposure to sound vibrations lead to transcriptomic, proteomic and hormonal changes in Arabidopsis. Sci. Rep. 6:33370.

Herbers, K., Meuwly, P., Métraux, J.-P. and Sonnewald, U. 1996. Salicylic acid-independent induction of pathogenesis-related protein transcripts by sugars is dependent on leaf developmental stage. FEBS Lett. 397:239-244.

Iida, H. 2014. Mugifumi, a beneficial farm work of adding mechanical stress by treading to wheat and barley seedlings. Front. Plant Sci. 5:453.

Kwon, Y. S., Lee, D. Y., Rakwal, R., Baek, S.-B., Lee, J. H., Kwak, Y.-S., Seo, J.-S., Chung, W. S., Bae, D.-W. and Kim, S. G. 2016. Proteomic analyses of the interaction between the plant-growth promoting rhizobacterium Paenibacillus polymyxa E681 and Arabidopsis thaliana. Proteomics 16:122135.

Kwon, Y. S., Ryu, C.-M., Lee, S., Park, H. B., Han, K. S., Lee, J. H., Lee, K., Chung, W. S., Jeong, M.-J., Kim, H. K. and Bae, D.-W. 2010. Proteome analysis of Arabidopsis seedlings exposed to bacterial volatiles. Planta 232:1355-1370.

Li, B., Wei, J., Wei, X., Tang, K., Liang, Y., Shu, K. and Wang, B. 2008. Effect of sound wave stress on antioxidant enzyme activities and lipid peroxidation of Dendrobium candidum. Colloids Surf. B Biointerfaces 63:269-275.

Li, Z.-G. and Gong, M. 2011. Mechanical stimulation-induced cross-adaptation in plants: an overview. J. Plant Biol. 54:358364.

Liu, G., Ji, Y., Bhuiyan, N. H., Pilot, G., Selvaraj, G., Zou, J. and Wei, Y. 2010. Amino acid homeostasis modulates salicylic acid-associated redox status and defense responses in Arabidopsis. Plant Cell 22:3845-3863.

Liu, Y., Ahn, J.-E., Datta, S., Salzman, R. A., Moon, J., Huyghues-Despointes, B., Pittendrigh, B., Murdock, L. L., Koiwa, H. and Zhu-Salzman, K. 2005. Arabidopsis vegetative storage protein is an anti-insect acid phosphatase. Plant Physiol. 139:1545-1556.

López-Ribera, I. and Vicient, C. M. 2017. Drought tolerance induced by sound in Arabidopsis plants. Plant Signal. Behav. 12:e 1368938.

Martinez, M., Abraham, Z., Gambardella, M., Echaide, M., Carbonero, P. and Diaz, I. 2005. The strawberry gene Cyfl encodes a phytocystatin with antifungal properties. J. Exp. Bot. 56:1821-1829.

Martinez-Medina, A., Flors, V., Heil, M., Mauch-Mani, B., Pieterse, C. M. J., Pozo, M. J., Ton, J., van Dam, N. M. and Conrath, U. 2016. Recognizing plant defense priming. Trends 
Plant Sci. 21:818-822.

Mishra, R. C., Ghosh, R. and Bae, H. 2016. Plant acoustics: in the search of a sound mechanism for sound signaling in plants. $J$. Exp. Bot. 67:4483-4494.

Monshausen, G. B. and Haswell, E. S. 2013. A force of nature: molecular mechanisms of mechanoperception in plants. $J$. Exp. Bot. 64:4663-4680.

Pastor, V., Luna, E., Mauch-Mani, B., Ton, J. and Flors, V. 2013. Primed plants do not forget. Environ. Exp. Bot. 94:46-56.

Peumans, W. J. and van Damme, E. J. M. 1995. The role of lectins in plant defence. Histochem. J. 27:253-271.

Qi, L., Teng, G., Hou, T., Zhu, B. and Liu, X. 2010. Influence of sound wave stimulation on the growth of strawberry in sunlight greenhouse. In: Computer and computing technologies in agriculture (III), eds. by D. L. Li and C. Zhao, pp. 449-454. Springer-Verlag Berlin Heidelberg, Heidelberg, Germany.

Rausch, T. and Wachter, A. 2005. Sulfur metabolism: a versatile platform for launching defence operations. Trends Plant Sci. 10:503-509.

Rojas, C. M., Senthil-Kumar, M., Wang, K., Ryu, C.-M., Kaundal, A. and Mysore, K. S. 2012. Glycolate oxidase modulates reactive oxygen species-mediated signal transduction during nonhost resistance in Nicotiana benthamiana and Arabidopsis. Plant Cell 24:336-352.

Safari, M., Ghanati, F., Behmanesh, M., Hajnorouzi, A., Nahidian, B. and Mina, G. 2013. Enhancement of antioxidant enzymes activity and expression of $C A T$ and $P A L$ genes in hazel (Corylus avellana L.) cells in response to low-intensity ultrasound. Acta Physiol. Plant. 35:2847-2855.

van Kan, J. A. L. 2006. Licensed to kill: the lifestyle of a necrotrophic plant pathogen. Trends Plant Sci. 11:247-253.

Wan, R., Hou, X., Wang, X., Qu, J., Singer, S. D., Wang, Y. and
Wang, X. 2015. Resistance evaluation of Chinese wild Vitis genotypes against Botrytis cinerea and different responses of resistant and susceptible hosts to the infection. Front. Plant Sci. 6:854.

Wang, B., Zhao, H., Wang, X., Duan, C., Wang, D. and Sakanishi, A. 2002. Influence of sound stimulation on plasma membrane H+-ATPase activity. Colloids Surf. B Biointerfaces 25:183188.

Wei, M., Yang, C.-Y. and Wei, S.-H. 2012. Enhancement of the differentiation of protocorm-like bodies of Dendrobium officinale to shoots by ultrasound treatment. J. Plant Physiol. 169:770-774.

Xiao, W., Sheen, J. and Jang, J.-C. 2000. The role of hexokinase in plant sugar signal transduction and growth and development. Plant Mol. Biol. 44:451-461.

Xiaocheng, Y., Bochu, W. and Chuanren, D. 2003. Effects of sound stimulation on energy metabolism of Actinidia chinensis callus. Colloids Surf. B Biointerfaces 30:67-72.

Xiujuan, W., Bochu, W., Yi, J., Defang, L., Chuanren, D., Xiaocheng, Y. and Sakanishi, A. 2003. Effects of sound stimulation on protective enzyme activities and peroxidase isoenzymes of chrysanthemum. Colloids Surf. B Biointerfaces 27:59-63.

Yi, J., Bochu, W., Xiujuan, W., Chuanren, D. and Xiaocheng, Y. 2003. Effect of sound stimulation on roots growth and plasmalemma H+-ATPase activity of chrysanthemum (Gerbera jamesonii). Colloids Surf. B Biointerfaces 27:65-69.

Zhang, Z., Ober, J. A. and Kliebenstein, D. J. 2006. The gene controlling the quantitative trait locus EPITHIOSPECIFIER $M O D I F I E R 1$ alters glucosinolate hydrolysis and insect resistance in Arabidopsis. Plant Cell 18:1524-1536. 